Discussion Paper No. 08-088

\title{
Impact of Service Station Networks on Purchase Decisions of Alternative-fuel Vehicles
}

Martin Achtnicht, Georg Bühler, and Claudia Hermeling

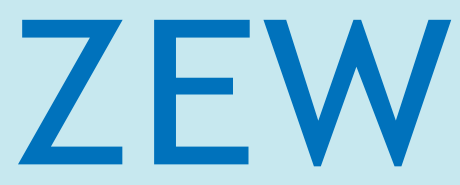

Zentrum für Europäische Wirtschaftsforschung $\mathrm{GmbH}$

Centre for European

Economic Research 
Discussion Paper No. 08-088

\title{
Impact of Service Station Networks on Purchase Decisions of Alternative-fuel Vehicles
}

\author{
Martin Achtnicht, Georg Bühler, \\ and Claudia Hermeling
}

Download this ZEW Discussion Paper from our ftp server:

ftp://ftp.zew.de/pub/zew-docs/dp/dp08088.pdf

Die Discussion Papers dienen einer möglichst schnellen Verbreitung von neueren Forschungsarbeiten des ZEW. Die Beiträge liegen in alleiniger Verantwortung der Autoren und stellen nicht notwendigerweise die Meinung des ZEW dar.

Discussion Papers are intended to make results of ZEW research promptly available to other economists in order to encourage discussion and suggestions for revisions. The authors are solely responsible for the contents which do not necessarily represent the opinion of the ZEW. 


\section{Executive Summary}

Motorized individual transport plays a major role in the political debate on climate change and energy security. About $26 \%$ of the entire $\mathrm{CO}_{2}$ emissions in the European Union result from the use of passenger cars. In addition, current passenger car transport heavily depends on oil. To reduce this oil dependency and $\mathrm{CO}_{2}$ emissions, the European Commission aims at substituting traditional automotive fuels by greener alternatives. However, such a strategy is based on the assumption that an acceptable level of infrastructure for new fuel types will be provided.

In this paper we study the impact of service station availability on the demand for alternative fuel vehicles. Our analysis of the consumers' preferences for such passenger cars is based on a stated preference (SP) experiment carried out in Germany. The interviewees should choose between conventional technologies (diesel or gasoline), more recent technologies (hybrid or gas) and future technologies (biofuels, electric or hydrogen).

To model the consumers' preferences a nested logit model is estimated. The estimated parameters show that sales price, variable costs and $\mathrm{CO}_{2}$ emissions have a negative impact on the purchase decision of a passenger car. Engine power and network density influences the choice positively. In addition, the analysis shows that the network density effect does not vary between people from rural and urban areas as well as between people with low and high annual mileage.

Based on the estimated model the willingness to pay for expanding the network density is computed. The higher the existing density is the lower is the willingness to pay for an expansion of the network. We find this correlation for both the sales price and the variable costs per $100 \mathrm{~km}$. Furthermore, our simulation results show that, in the case of a full service station network of all technologies, LPG/CNG and hydrogen cars would achieve substantial market shares. However, the biofuels and electric power trains are well behind. 


\section{Das Wichtigste in Kürze}

Der motorisierte Individualverkehr spielt in der klima- und energiepolitischen Diskussion eine zentrale Rolle. Etwa 26\% der gesamten $\mathrm{CO}_{2}$ Emissionen in der Europäischen Union sind auf den Pkw-Verkehr zurückzuführen. Die Europäische Kommission strebt daher eine Förderung alternativer Antriebstechnologien und Treibstoffe an, um den $\mathrm{CO}_{2}$ Ausstoß und die Abhängigkeit vom Öl zu reduzieren. Voraussetzung dafür ist die Existenz einer ausgebauten Tankstellen-Infrastruktur.

In diesem Papier wird der Einfluss des Tankstellennetzes auf die Nachfrage nach Fahrzeugen mit alternativen Kraftstoffen untersucht. Die Analyse der Kundenpräferenzen basiert auf einem Conjoint-Experiment, das im Rahmen eines BMBF-Projektes in Deutschland durchgeführt wurde. Neben konventionellen (Diesel und Benzin) und moderneren Technologien (Hybrid und Gas), standen den Probanden dabei auch Zukunftstechnologien wie Wasserstoff, Elektro und Biokraftstoffe zur Auswahl.

Im Rahmen der ökonometrischen Analyse wird ein genistetes Logit-Modell zur Abbildung der Kundenpräferenzen geschätzt. Die geschätzten Parameter zeigen, dass neben dem Kaufpreis und den variablen Kosten auch die $\mathrm{CO}_{2}$-Emissionen einen negativen Einfluss auf die Kaufentscheidung haben. Die Größe des Tankstellenetzes hingegen wirkt sich positiv aus. Der Einfluss der Tankstellen-Infrastruktur auf die Kaufentscheidung ist hierbei unabhängig vom Wohnort (urban vs. rural) und der anvisierten jährlichen Fahrleistung eines PKW-Käufers. Aus der ökonometrischen Analyse werden die Zahlungsbereitschaften für eine Erweiterung des Tankstellennetzes abgeleitet.

Basierend auf dem geschätzten Modell werden verschiedene Szenarien simuliert. Es zeigt sich, dass Gas-, Hybrid- und Wasserstofffahrzeuge einen substantiellen Marktanteil durch Ausbau ihres Tankstellennetzes erreichen können. Biokraftstoffund Elektrofahrzeuge hingegen würden auch bei vollständig entwickelter Infrastruktur deutlich seltener nachgefragt. 


\title{
Impact of service station networks on purchase decisions of alternative-fuel vehicles
}

\author{
Martin Achtnicht, Georg Bühler, and Claudia Hermeling*
}

October 31, 2008

\begin{abstract}
In this paper we analyze the impact of service station availability on the demand for alternative-fuel vehicles and the consumers' willingness to pay for an enlarged fueling infrastructure. We examine a stated preferences choice experiment conducted as a CAPI survey with about 600 interviews of potential car buyers in Germany and estimate the coefficients of a discrete choice model. We simulate different scenarios and analyze how individual choice probabilities for alternative fuel-types are changing with a modified fueling infrastructure. In our scenarios hybrids, LPG/CNG and hydrogen will be real alternatives to the existing conventional technologies. However, biofuels and electric power trains are well behind even in a situation where their infrastructure is equally developed. Moreover, on the basis of our model we compute what increases in fixed or variable costs consumers of different income groups are willing to accept for an increasing station density. JEL classification: C51, L62, R41.
\end{abstract}

Keywords: Fueling Infrastructure; Alternative Fuels; Automobile Market; Stated Preferences; Discrete Choice; Network Effects.

\footnotetext{
${ }^{*}$ Centre for European Economic Research (ZEW), L7,1, D-68161 Mannheim, Germany; Emails: achtnicht@zew.de, buehler@zew.de, hermeling@zew.de This paper was written within the research project "ECO-CARS". We would like to thank our partners in this project for helpful discussions and suggestions and the German Federal Ministry of Education and Research (BMBF) for financial support.
} 


\section{Introduction}

Motorized individual transport plays a major role in the current political debate on climate change and energy security. According to the European Commission, transport accounts for some $71 \%$ of oil consumption and for $26 \%$ of $\mathrm{CO}_{2}$ emissions in the European Union(Source). The automobile sector alone depends on oil at $98 \%$. To reduce oil dependency and to make transport more sustainable, the Commission set out an objective to substitute $20 \%$ of traditional automotive fuels with alternatives by the year 2020 (EU (2000), EU (2006)). But a penetration of the market with alterative fuels requires an acceptable level of infrastructure.

In this paper we study the impact of service station availability on the demand for alternative-fuel vehicles. The lack of a widespread fueling station network for alternative fuels may constitute a barrier to the entry of alternative-fuel vehicles into the market. Additionally, network externalities arising from the existence of the installed fueling infrastructure for gasoline and diesel may deter consumers to switch to new incompatible technologies. In the literature this problem is referred to as "excess inertia" (Farell and Saloner (1986)).

However, the expansion of the fueling station networks for alternative fuels requires high investments. Reducing or replacing filling pumps for fossil fuels by others will be only profitable for service station owners if the demand, i.e. the number of vehicles using alternative-fuels, considerably increases.

The complementary of vehicle demand and fueling infrastructure supply is often described as chicken-egg problem and raises the question of political intervention. But are public subsidies for the development of an alternative fueling station network really necessary? How much are the consumers willing to pay for a network expansion? Will the consumer really switch to vehicles running on alternative fuels if a fully developed station network exists?

Based on a stated preferences choice experiment we try to answer these questions for the German market. We analyze car purchase decision for a broad set of existing fossil fuel based and future alternative fuel based propulsion technologies. Our analysis is based on a stated preference (SP) experiment conducted as a computer assisted personal interview (CAPI) with about 600 interviews of potential car buyers in Germany. Using a nested logit model, we estimate the impact of the fueling station network on the purchase decision of passenger cars running with 
alternative fuel types. We show that the impact of a larger service station network on the purchase decision is positive with a diminishing marginal utility. We identify the influence of different socio-demographic and socio-economic characteristics and the ecological attitude on individual choice probabilities. We can not confirm the hypothesis that consumers with intensive car use are more sensitive regarding fueling infrastructure. Likewise, we found no empirical evidence for a varying effect of the service station network on different fuel types. In this regard, new technologies have no systematical disadvantage compared to conventional technologies.

To illustrate the impact of service station availability on the purchase decision for passenger cars, we simulate different scenarios and analyze how the choice probabilities for alternative fuel-types are changing with a modified fueling infrastructure. We show that an enlargement of infrastructure for alternative fuel-types will raise the market shares of hybrids, LPG/CNG and hydrogen considerably. Thus, these alternative technologies can be seen as real alternatives to existing conventional technologies. On the other hand, biofuels and electric power train are well behind even in a situation where their infrastructure is equally developed.

Moreover, on the basis of our model we compute the absolute and relative willingness to pay (WTP) for an enlarged fueling station network and show how it differs in relation to the income of the consumers. We find that the relative WTP for an enlargement of the infrastructure decreases with the size of the existing fueling network and with an increasing purchase prices of a vehicle. However, for very expensive cars the relative WTP increases again. The amount of additional variable costs the consumers are willing to accept for an enhanced network is just as well decreasing in the size of the already existing network.

The paper is organized as follows. In section 2 we describe the survey and the data set. Section 3 introduces our discrete choice model. Section 4 displays our estimation results with the presentation of the coefficients in subsection 4.1, the description of the simulations in subsection 4.2, and the computation of the willingness to pay in subsection 4.3. The last section discusses the results and concludes. 


\section{Description of the survey}

The estimations in this paper are based on a German-wide consumer survey amongst potential car-buyers. This survey was designed to estimate their preferences for cars with alternative technologies and fuel types by creating choice situations with hypothetical vehicles. It was conducted in the framework of the research project ECO-CARS ${ }^{1}$.

Available datasets concerning car purchase decisions do not deliver sufficient information for our analysis due to their focus on already existing technologies. They are based upon historical data and do not cover new technologies like electric or hydrogen cars which are actually not available in the market. Moreover, technologies like hybrids, CNG and LPG or conventional cars using biofuels with a negligible market penetration are not sufficiently represented in the databases (Horne et al. (2005)). In addition, details on the socio-demographic and socioeconomic status of the interviewees are often missing. But these information are expected to be relevant for the choice decision of passenger cars (Dragay (2001)).

The survey was conducted from August 2007 to March 2008 as a computer assisted personal interview (CAPI) in Germany. The interviewers were requested to ask consumers of all population groups. Restrictions were made only for the age of the respondents. They should be of age and have a valid driving license. We interviewed about 600 people living in different regions in Germany (East- vs. West-Germany, urban vs. rural areas). The interviews took place in showrooms of car dealers from different brands and in selected offices of the technical inspection authority.

The survey consists of a multi-sectional questionnaire. The respondents are asked for socio-demographic and -economic details and for their actual car ownership. They are asked whether they intend or at least could imagine to replace an existing car or to buy a new car. In these cases the respondents were ask for further details about the envisaged vehicle. An additional set of questions covered mobility patterns and car use with a special focus on environmental-friendly behavior.

The core of the questionnaire is a stated preference (SP) choice experiment

\footnotetext{
${ }^{1}$ Further details about the project ECO-CARS can be found here: http://kooperationen.zew.de/en/eco-cars/home.html
} 
concerning a car purchase decision. Each respondent have to answer six choice sets. Each choice set consists of seven alternative vehicles, each characterized by the six following attributes:

- Selling price of a vehicle.

- Variable costs per 100 kilometers.

- Engine power.

- $\mathrm{CO}_{2}$ emissions.

- Fuel availability (given by the size of the service station network).

- Fuel type.

Selling price, variable costs and engine power are standard explanatory variables in vehicle choice models (Horne et al. (2005), Ewing and Sarigollu (2000), Brownstone et al. (2000), McCarthy and Tay (1998), McCarthy (1996), Bunch et al. (1993) as well as Manski and Sherman (1980)). $\mathrm{CO}_{2}$ emissions and fuel availability are used in just a few surveys (Horne et al. (2005), Brownstone et al. (2000) and Bunch et al. (1993)).

Table 1 illustrates the possible values of the attributes in our choice experiment. The SP-experiment is quasi-labeled. Each fuel type is covered once in each choice set and can therefore be handled as a label of the alternatives. But the presentation of the choice sets is designed as an unlabeled SP-experiment such that the fuel type looks like an attribute of a car and not as an alternative itself.

To create a realistic choice situation the respondents were ask beforehand to characterize the vehicle they could imagine to buy. This characterization referred to the car classification (full-size, compact, mid-size, Van, sports car, ...) as well as to the selling price and engine power. The possible values of the selling price and engine power in the SP-experiment were equal to $75 \%, 100 \%$ and $125 \%$ of the values given by the respondent. Although this determination causes some correlation between selling price and engine power it avoids unimaginable situations for the respondent. ${ }^{2}$

The set of possible $\mathrm{CO}_{2}$ values differs with respect to the fuel types. There are always strictly positive emissions of vehicles running on fossil fuels like diesel,

\footnotetext{
${ }^{2}$ In reality, selling price and engine price are correlated. More expensive cars usually have a higher engine performances than inexpensive cars. Such correlations are typical for revealed purchase decisions (Fowkes and Wardman (1988)).
} 


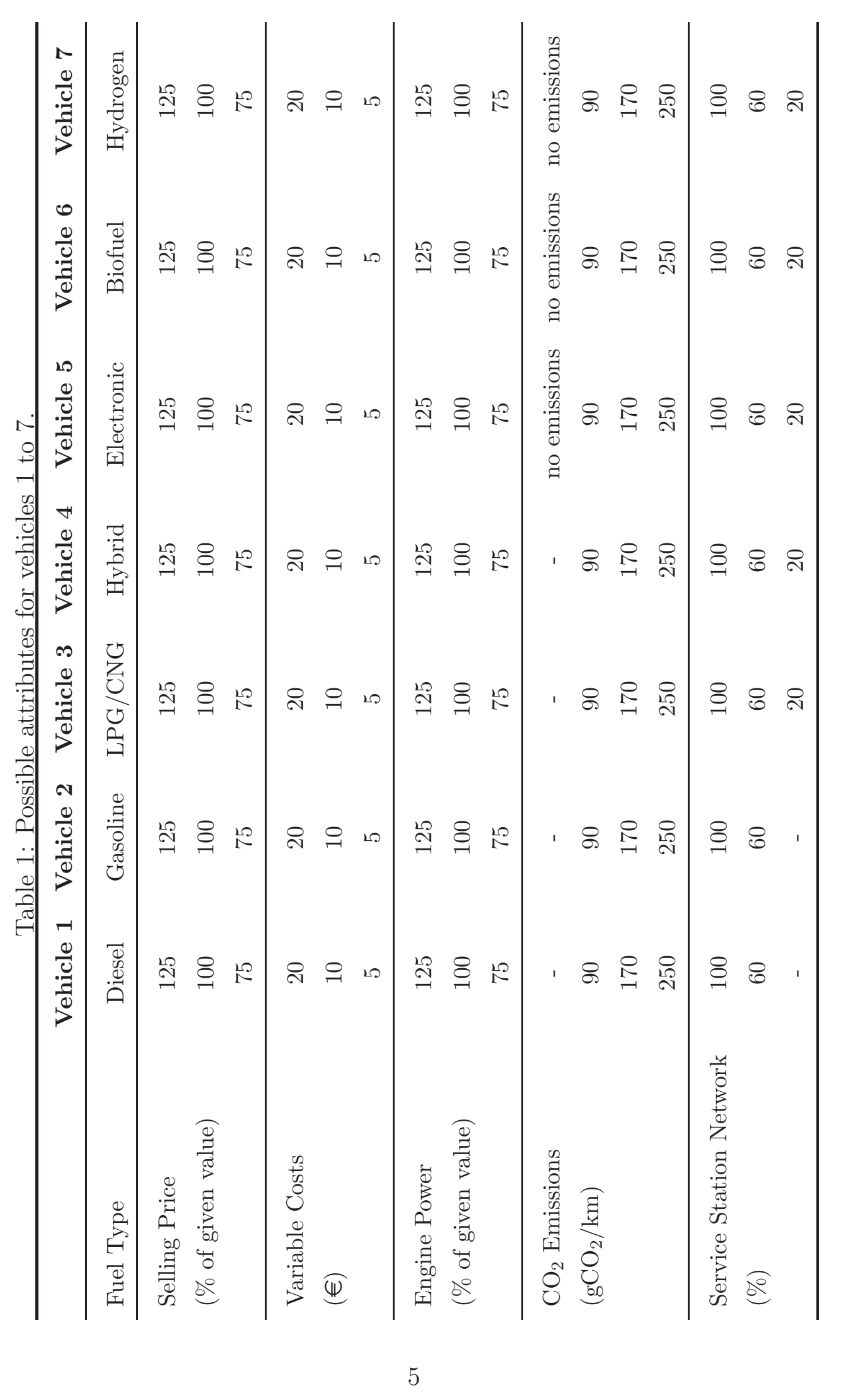


gasoline, CNG or LPG. But we include the alternative "no emissions" for electronic, hydrogen or biofuel driven cars because their $\mathrm{CO}_{2}$ emissions are zero. But because emissions emerge in the course of fuel-production, we allow positive $\mathrm{CO}_{2}$ emissions.

\section{The model specification}

Choice decisions are characterized by a discrete outcome. To analyze them it requires the use of discrete choice models (DCM). Such models owe their theoretical grounding in microeconomics especially to McFadden and his random utility approach (McFadden 1974). A utility $U_{n j}$ provided by an alternative $j$ to an person $n$ is assumed to be

$$
U_{n j}=V_{n j}\left(x_{j}, z_{n}\right)+\varepsilon_{n j},
$$

where $V_{n j}\left(x_{j}, z_{n}\right)$ is a deterministic (observed) utility component, depending on attributes $x_{j}$ of alternative $j$ and sociodemographic variables $z_{n}$ of person $n$, and $\varepsilon_{n j}$ is a (unobserved) stochastic component. ${ }^{3}$ According to the economic theory of the utility-maximizing individual, person $n$ will choose that alternative from the set $\{1, \ldots, J\}$ of alternatives that provides him the greatest utility. Since utility is modeled as a random variable, however, only choice probabilities can be econometrically estimated. Depending on the assumptions made about the distribution of the random variables $\varepsilon_{n j}(n=1, \ldots, N ; j=1, \ldots, J)$, different discrete choice models are defined (cf., for instance, Train 2003).

In this paper, we use a nested logit model to analyze the choice decisions for passenger cars running with alternative fuel types. Likewise in multinomal logit models (MNL), the marginal distributions of the $\varepsilon_{n j}$ 's are univariate extreme value. But by portioning similar alternatives into subsets $B_{k}(k=1, \ldots, K)$ (so called nests), we virtually allow the associated $\varepsilon_{n j}$ to be correlated. Hence, we can relax the independence from irrelevant alternatives (IIA) assumption regarding alternatives in different nests. For example McFadden (1978) showed that this model specification results in the following choice probability that person $n$ chooses alternative $i \in B_{k}$ :

\footnotetext{
${ }^{3}$ For a discussion on the use of unobserved components see Ben-Akiva and Lerman (1985).
} 


$$
P_{n i}=\frac{e^{V_{n i} / \lambda_{k}}\left(\sum_{j \in B_{k}} e^{V_{n j} / \lambda_{k}}\right)^{\lambda_{k}-1}}{\sum_{l=1}^{K}\left(\sum_{j \in B_{l}} e^{V_{n j} / \lambda_{l}}\right)^{\lambda_{l}}},
$$

where $\lambda_{k}$ is called dissimilarity parameter of nest $B_{k}$ and captures the degree of independence among the alternatives in $B_{k}{ }^{4}$ To be consistent with utilitymaximizing behavior for all values of the independent variables the $\lambda_{k}$ 's need to be between zero and one. ${ }^{5}$

In our case, we partitioned the seven alternative fuel types into four nests. The first nest contains gasoline and diesel and can be described as the conventional technology nest. Within this nest the technologies are well established and have substantial market shares. Technologies that already entered the market in the past few years but currently have a small market share could be allocated into a second nest. However, we belief that hybrids and LPG/CNG differ fundamentally. ${ }^{6}$ Consequently, we decide to model two separate degenerated nests ${ }^{7}$ for the two alternatives hybrid and LPG/CNG. The fourth nest can be described as the future technology nest, containing all technologies which have not already entered the market. Some of these technologies are close to market penetration, others are not. Nevertheless we cannot identify a substantial reason to build more than one nest for these technologies. Figure 1 displays the structure of the nested logit model.

The independent variables that enter our model and the underlying hypotheses are briefly discussed in the following. The deterministic component of utility $V$ is as usual - specified linearly in parameters. As indicated in section 2 the attributes describing the seven alternatives are the purchase price, variable costs, engine power, $\mathrm{CO}_{2}$ emissions and the density of the fueling station network. While the

\footnotetext{
${ }^{4}$ Heiss (2002) compares different specifications of nested logit models and shows that this one (so called random utility maximization nested logit (RUMNL)) is preferable in most situations. He also introduces an implementation of RUMNL in Stata.

${ }^{5}$ Nested logit models might also be locally consistent with utility maximization if $\lambda_{k}>1$. Herriges and Kling (1996) present a useful test of consistency in this regard.

${ }^{6}$ To a substantial share hybrid vehicles use the same fuel type like the alternatives in the first nest. In addition hybrids run on electricity which requires a different engine technology. On the other hand, LPG or CNG passenger cars use another kind of fuel but the same engine technology like gasoline cars.

${ }^{7}$ Since dissimilarity parameters of degenerate nests are not identified in the RUMNL model, they have to be restricted to a nonzero constant (Heiss 2002). We choose 1 for this restriction.
} 


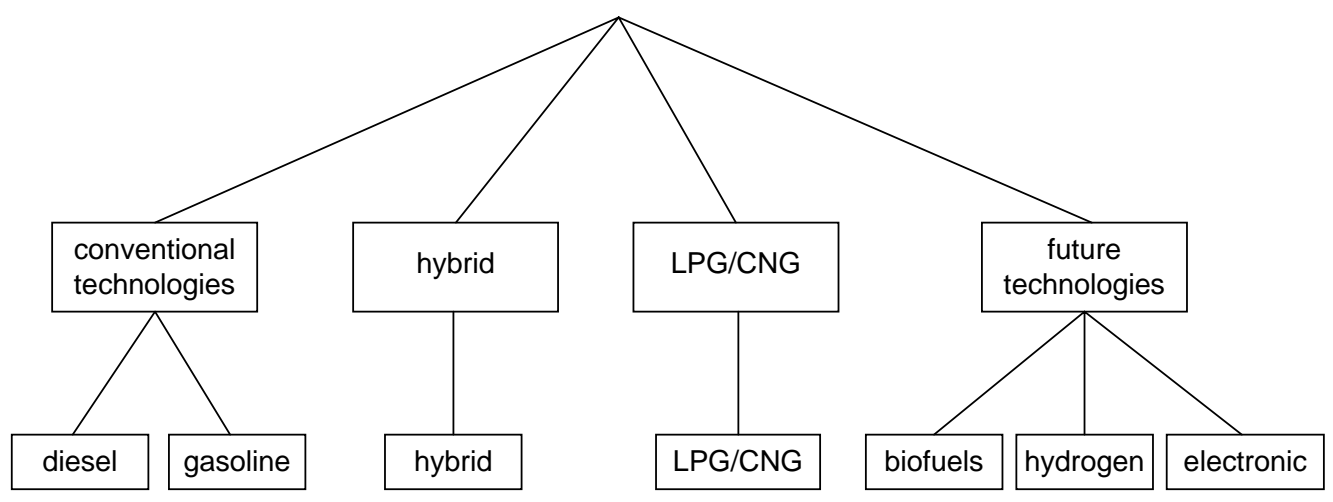

Figure 1: Structure of the nested logit model

correlation between the purchase price, the variable costs and the $\mathrm{CO}_{2}$ emissions with the choice probability is expected to be negative, it should be positive for the engine power and the density of the network.

Concerning the network density effect it might be assumed that the impact on the choice probability varies between the available alternatives. New technologies might have a disadvantage compared to conventional technologies because of the skepticism they are confronted with. To control for these differences we generate interaction variables. Furthermore it might be expected that persons with an intensive use of the passenger cars wish to have a higher network density which guarantees more flexibility in the use of the passenger car. This relation is captured by the annual mileage covered by the passenger car and by the maximum distance that can be covered by one refueling process.

We moreover describe the impact of specific sociodemographic characteristics on respondents' stated choice decision. Firstly, we focus on the eco-orientation of the consumers. We assume that consumers with a higher attitude for environmental friendly goods have a stronger focus on the $\mathrm{CO}_{2}$ emissions performance of passenger cars, too. Therefore we asked the interviewees about their eco-orientation by a sequence of questions describing choice decisions in several situations of daily life. Depending on their answers they scored a certain level on a defined ecoscale. People who scored more on this eco-scale than the sample mean are defined as ecologically motivated, consumers who did not, consistently, as ecologically not motivated. Secondly, we assume that older consumers have some prejudices against innovative products (Carlsson-Kanyama et al. (2005)). Estimating the effect of 
the consumers' age on the car purchase decision of new technologies is expected to be negative. Thirdly, the income of the household will have an impact on the car purchase decision. We assume that consumers with a low income are more price-sensitive.

\section{Empirical results}

\subsection{Coefficients}

Table 2 shows the estimation results. ${ }^{8}$ The coefficient of the purchase price has, as expected, a negative sign and is highly statistically significant, whereas the square of the purchase price is positively signed. This indicates a diminishing marginal disutility. This means: the higher the price of a passenger car, the greater the disutility - but paying an additional Euro is hurting less if the price is already relatively high. Further analysis of the price-utility relation reveals a maximum disutility at a price of 145000 Euro, approximately. One could assume that in such price categories consumers derive benefit simply from the fact that the car is that expensive. However, the average prices stated by the respondents range from 525 to 125000 Euro. ${ }^{9}$ Therefore, the estimated utility function is particularly valid for this range - where it behaves normally. Our estimation results moreover confirm the hypothesis that the lowest income group of respondents (i.e. household income below 1000 Euro) is more price-sensitive. Their price coefficient (which is the sum of "Purchase Price" and "PriceXIncomeBelow1000") is clearly lower than the one for the reference group (i.e. individuals with a household income above 2000 Euro). This implies a lower WTP for improvements regarding passenger car attributes. $^{10}$

As expected, the coefficient for variable costs is negative and the one for engine power is positive, the related quadratic terms are both not significant. In contrast to the purchase price, every Euro which increases the variable costs of car use

\footnotetext{
${ }^{8}$ Interaction terms regarding different fuel types have to be interpreted with reference to the baseline alternative diesel.

${ }^{9} \mathrm{We}$ asked the respondents to indicate a lower and an upper bound for the purchase price of their next car, and then used the average to design individual choice sets.

${ }^{10}$ We will consider this in our discussion about WTP for an enlarged fueling infrastructure below.
} 
burdens equally. So, consumers differentiate clearly between one-off costs and recurring costs.

The estimation furthermore shows that ecologically motivated consumers are more concerned about $\mathrm{CO}_{2}$ emissions in their car purchase decision. ${ }^{11}$ This is remarkable, though not surprising. But the negative sign of the quadratic $\mathrm{CO}_{2}$ term suggests that there is an increasing marginal disutility of $\mathrm{CO}_{2}$ emissions for all people. It seems that the ongoing debates about $\mathrm{CO}_{2}$ emissions as the driving factor for climate change have their impacts. People are aware of the problem, and they are not willing to accept arbitrary many $\mathrm{CO}_{2}$ emissions due to their car driving.

Besides, we checked whether sociodemographic or other individual variables influence the utility of the alternatives. Our results show that ecologically motivated people prefer alternative fuel types - compared to diesel - more clearly than people do, who are not ecologically motivated. Older people, however, seem to have some prejudices against future technologies, particularly against electric and hydrogen cars. Hence, the probability to choose conventional cars increases with the age of the respondent. The estimation further shows that the larger the preferred range and the planned annual mileage, the more likely a diesel-driven car is to be chosen. Although respondents were asked to assume that all presented alternatives of a choice set equal in omitted attributes, it seems that experienced economic advantages of diesel-driven cars are causing this.

The impact that a larger service station network has on the purchase decision is positive with a diminishing marginal utility. This effect does not vary between people from rural and urban areas and does not depend on the preferred range or the planned annual mileage. So, we can not confirm our hypothesis that people with intensive car use are more sensitive regarding the fueling infrastructure. It rather seems that flexibility, guaranteed by a dense service station network, is equally important to all passenger car drivers. Likewise, there is no empirical evidence in our data for a varying effect of the service station network on different fuel types (compared to our reference alternative diesel). For consumers it is just important that there is a network, no matter for which specific technology. In this regard, new technologies have no systematical disadvantage compared to

\footnotetext{
${ }^{11}$ In our sample the majority of people is ecologically motivated. So we used them as reference and checked for differences to not motivated people with the help of interaction terms.
} 
conventional technologies. An additional barrier in terms of market penetration does not exist for future technologies.

Table 2: Coefficients of the estimated nested logit model.

\begin{tabular}{lclc}
\hline Explanatory Variables & Coefficient & StdErr & t-value \\
\hline Gasoline & $1.685591^{* * *}$ & 0.4256968 & 3.96 \\
Hybrid & $1.324387^{* * *}$ & 0.4635192 & 2.86 \\
LPG/CNG & $2.235748^{* * *}$ & 0.4592655 & 4.87 \\
Biofuels & $1.276084^{* * *}$ & 0.4584939 & 2.78 \\
Hydrogen & $1.441803^{* * *}$ & 0.439613 & 3.28 \\
Electronic & 0.7485304 & 0.4742836 & 1.58 \\
Purchase Price & $-0.0000557^{* * *}$ & $7.94 \mathrm{e}-6$ & -7.02 \\
Purchase Price2 & $1.92 \mathrm{e}-10^{* * *}$ & $7.18 \mathrm{e}-11$ & 2.67 \\
PriceXIncomeBelow1000 & $-0.0001091^{*}$ & 0.0000555 & -1.96 \\
PriceXIncomeBetween1000and2000 & 0.0000219 & 0.0000142 & 1.54 \\
Variable Costs & $-0.0882831^{* * *}$ & 0.0200931 & -4.39 \\
Variable Costs2 & 0.000629 & 0.0007997 & 0.79 \\
Engine Power & $0.0079624^{* * *}$ & 0.0014932 & 5.33 \\
Engine Power2 & $-5.44 \mathrm{e}-6$ & $3.50 \mathrm{e}-6$ & -1.55 \\
CO2 Emissions & $-0.0032838^{* * *}$ & 0.0009438 & -3.48 \\
CO2 Emissions2 & $-6.85 \mathrm{e}-6^{* *}$ & $3.29 \mathrm{e}-6$ & -2.08 \\
CO2XNonEcologists & $0.0020165^{* * *}$ & 0.0006079 & 3.32 \\
Service Station Network & $0.0233777^{* * *}$ & 0.0063087 & 3.71 \\
Service Station Network2 & $-0.0001023^{* * *}$ & 0.0000347 & -2.95 \\
NetworkXRuralArea & 0.0009867 & 0.0013007 & 0.76 \\
NetworkXRange & -0.0009815 & 0.0013319 & -0.74 \\
NetworkXMileage & 0.0003688 & 0.001328 & 0.28 \\
GasolineXNetwork & 0.0013404 & 0.003329 & 0.40 \\
HybridXNetwork & 0.0032981 & 0.0034072 & 0.97 \\
LPG/CNGXNetwork & 0.0006386 & 0.0034033 & -0.19 \\
BiofuelXNetwork & 0.000948 & 0.0032649 & 0.29 \\
HydrogenXNetwork & 0.003426 & 1.44 \\
ElectronicXNetwork & 0.1168687 & 0.88 \\
GasolineXNonEcologists & &
\end{tabular}




\begin{tabular}{llll}
\hline Explanatory Variables & Coefficient & StdErr & t-value \\
\hline HybridXNonEcologists & $-0.4444745^{* * *}$ & 0.1430908 & -3.11 \\
LPG/CNGXNonEcologists & $-0.3563097^{* *}$ & 0.1411524 & -2.52 \\
BiofuelXNonEcologists & $-0.5178417^{* * *}$ & 0.1538032 & -3.37 \\
HydrogenXNonEcologists & $-0.6262525^{* * *}$ & 0.1430078 & -4.38 \\
ElectronicXNonEcologists & $-0.4801181^{* * *}$ & 0.160911 & -2.98 \\
GasolineXRange & $-0.0030094^{* * *}$ & 0.000429 & -7.01 \\
HybridXRange & $-0.0019316^{* * *}$ & 0.0004425 & -4.37 \\
LPG/CNGXRange & $-0.0027116^{* * *}$ & 0.0004447 & -6.10 \\
BiofuelXRange & $-0.0022286^{* * *}$ & 0.0004435 & -5.02 \\
HydrogenXRange & $-0.0011233^{* * *}$ & 0.0003971 & -2.83 \\
ElectronicXRange & $-0.0009531^{* *}$ & 0.0004447 & -2.14 \\
GasolineXMileage & $-0.0000221^{* * *}$ & $4.84 \mathrm{e}-6$ & -4.57 \\
HybridXMileage & $-0.0000116^{* *}$ & $4.85 \mathrm{e}-6$ & -2.39 \\
LPG/CNGXMileage & $-0.00001^{* *}$ & $4.85 \mathrm{e}-6$ & -2.06 \\
BiofuelXMileage & $-3.44 \mathrm{e}-6$ & $4.34 \mathrm{e}-6$ & -0.79 \\
HydrogenXMileage & $-6.54 \mathrm{e}-6$ & $4.06 \mathrm{e}-6$ & -1.61 \\
ElectronicXMileage & $-4.67 \mathrm{e}-6$ & $4.46 \mathrm{e}-6$ & -1.05 \\
GasolineXAge & $0.0109605^{* * *}$ & 0.0038356 & 2.86 \\
HybridXAge & -0.0036411 & 0.0046592 & -0.78 \\
LPG/CNGXAge & $-0.0089882^{*}$ & 0.0046419 & -1.94 \\
BiofuelXAge & -0.0064626 & 0.0047191 & -1.37 \\
HydrogenXAge & $-0.0155903^{* * *}$ & 0.0043976 & -3.55 \\
ElectronicXAge & $-0.0209377^{* * *}$ & 0.0050959 & -4.11 \\
\hline$\lambda_{\text {conv }}$ & $0.9181889^{* * *}$ & 0.0857245 & 10.71 \\
$\lambda_{\text {hybrid }}$ & 1 & $\cdot$ & $\cdot$ \\
$\lambda_{\text {LPG/CNG }}$ & $0.8461599^{* * *}$ & 0.0681653 & 12.41 \\
$\lambda_{\text {future }}$ & & & \\
& & & $\cdot$ \\
\hline & & & \\
\hline
\end{tabular}

Significance level: ${ }^{* * *} p<0.01,{ }^{* *} p<0.05,{ }^{*} p<0.1$ 


\subsection{Simulations}

To illustrate what impact the service station availability actually has on the purchase decision for passenger cars, we simulate different scenarios. Based on our estimated model we analyze how the average choice probabilities ${ }^{12}$ for alternative fuel-types are changing with a modified fueling infrastructure. Therefore we underlie a standard car defined by the average attribute levels occurring in our data set. More precisely, we set a purchase price of 20740 Euro, variable costs of 11.67 Euro/100 km, engine power of 127 PS and $\mathrm{CO}_{2}$ emissions of $130 \mathrm{~g} / \mathrm{km}$ for the standard car. The only attribute that we let vary between the different propulsion technologies is the network density.

In scenario 1 we look at a simplified version of the status quo in Germany. For gasoline-, diesel-driven cars and hybrids almost every fueling station is convenient (100\% network density). The network density of LPG/CNG and biofuels are set to $30 \%$ and $13 \%$, respectively. Regarding the rather embryonic technologies hydrogen and electronic power train we set a network density of $1 \%$ to simplify matters. The resulting average choice probabilities indicate that those propulsion technologies are demanded most for which the highest network density is provided. Gasoline-, diesel-driven cars and hybrids are all around 25\% - with slight advantages for the conventional technologies. On average, LPG/CNG cars with their 30\% network density definitely have a fair chance to be chosen (10.7\%). However, biofuels, hydrogen and electronic cars only have minor potentialities in such a situation. Interestingly, the choice probability for hydrogen $(4.8 \%)$ is even higher than the one for biofuels $(4.3 \%)$ - although the latter are equipped with a rather developed infrastructure. Due to the recently recognized coherences between subsidized biofuels and increasing food prices, the commonly image of biofuels is worsened. It might be that this development is reflected in our sample.

Throughout the scenarios 2 to 6 we continuously increase the network densities of LPG/CNG and future technologies up to 100\%. Although this conforms the rather naive idea that all regarded technologies are advancing likewise, it nevertheless gives an insight on how the situation could look like if the network den-

\footnotetext{
${ }^{12}$ At first, the choice probabilities are predicted separately for every respondent within our data set, and then these predicted probabilities are averaged. If the sample would be representative, the average probabilities could be interpreted as potential market shares.
} 
Table 3: Underlying network densities (\%) of simulated scenarios.

\begin{tabular}{lrrrrrr}
\hline Scenario & $\mathbf{1}$ & $\mathbf{2}$ & $\mathbf{3}$ & $\mathbf{4}$ & $\mathbf{5}$ & $\mathbf{6}$ \\
\hline Gasoline & 100 & 100 & 100 & 100 & 100 & 100 \\
\hline Diesel & 100 & 100 & 100 & 100 & 100 & 100 \\
\hline Hybrid & 100 & 100 & 100 & 100 & 100 & 100 \\
\hline LPG/CNG & 30 & 50 & 70 & 90 & 100 & 100 \\
\hline Biofuels & 13 & 30 & 50 & 70 & 90 & 100 \\
\hline Hydrogen & 1 & 30 & 50 & 70 & 90 & 100 \\
\hline Electric & 1 & 30 & 50 & 70 & 90 & 100 \\
\hline
\end{tabular}

Table 4: Choice probabilities in simulated scenarios.

\begin{tabular}{lrrrrrr}
\hline Scenario & $\mathbf{1}$ & $\mathbf{2}$ & $\mathbf{3}$ & $\mathbf{4}$ & $\mathbf{5}$ & $\mathbf{6}$ \\
\hline Gasoline & $27.2 \%$ & $24.5 \%$ & $22.3 \%$ & $20.5 \%$ & $19.4 \%$ & $19.0 \%$ \\
\hline Diesel & $27.1 \%$ & $24.2 \%$ & $22.0 \%$ & $20.2 \%$ & $19.0 \%$ & $18.7 \%$ \\
\hline Hybrid & $23.7 \%$ & $21.2 \%$ & $19.1 \%$ & $17.5 \%$ & $16.5 \%$ & $16.1 \%$ \\
\hline LPG/CNG & $10.7 \%$ & $12.7 \%$ & $14.2 \%$ & $14.9 \%$ & $14.5 \%$ & $14.2 \%$ \\
\hline Biofuels & $4.3 \%$ & $5.4 \%$ & $7.0 \%$ & $8.5 \%$ & $9.7 \%$ & $10.1 \%$ \\
\hline Hydrogen & $4.8 \%$ & $8.0 \%$ & $10.0 \%$ & $11.5 \%$ & $12.7 \%$ & $13.0 \%$ \\
\hline Electric & $2.1 \%$ & $4.0 \%$ & $5.4 \%$ & $6.9 \%$ & $8.3 \%$ & $9.0 \%$ \\
\hline
\end{tabular}

sity would no longer differ between fuel-types. The results of scenario 6 show that gasoline- (19\%) and diesel-driven cars (18.7\%) would keep ahead of others, but their lead would dwindle considerably. In addition to hybrids (16.1\%) and LPG/CNG (14.2\%), hydrogen (13\%) would now also be a real alternative to the conventional propulsions. According to present preferences, biofuels (10.1\%) and electric power train (9\%) would be rated worst. We already mentioned above possible drawbacks of biofuels. Regarding electric drive train it could well be that existing practical difficulties (e.g. long charging, short range) are known by the respondents and made it less attractive for them. The scenarios and the corresponding simulation results are shown in detail in tables 3 and 4, respectively. 
Table 5: Choice probabilities depending on ecological attitude.

\begin{tabular}{lcc}
\hline & $\begin{array}{c}\text { Scenario } \mathbf{6 b} \\
\text { negative ecological attitude } \\
\text { of the standard individual }\end{array}$ & $\begin{array}{c}\text { Scenario 6c } \\
\text { positive ecological attitude } \\
\text { of the standard individual }\end{array}$ \\
\hline Gasoline & $23.2 \%$ & $15.8 \%$ \\
Diesel & $21.1 \%$ & $16.0 \%$ \\
Hybrid & $15.0 \%$ & $17.8 \%$ \\
LPG/CNG & $13.7 \%$ & $14.8 \%$ \\
Biofuels & $9.0 \%$ & $11.4 \%$ \\
Hydrogen & $10.3 \%$ & $14.8 \%$ \\
Electric & $7.7 \%$ & $9.4 \%$ \\
\hline
\end{tabular}

Based on the situation given by scenario 6 (i.e. all technologies are provided with a network density of $100 \%$ ) we furthermore examine what impact the ecological attitude of people has on individual choice probabilities. Therefore, we underlie a standard individual defined by the average levels of sociodemographic and other individual variables occurring in our data set. This person is 45 years of age and lives in a household in a rather urban area with a net income of more than 2000 Euro. He prefers a range of $630 \mathrm{~km}$ and plans an annual mileage of $19500 \mathrm{~km}$ with his new car (both values are slightly below the sample average). But in the one case he is ecologically motivated (scenario 6c) and in the other he is not (scenario 6b). The differences in the resulting choice probabilities are striking. In scenario 6b gasoline (23.2\%) and diesel $(21.1 \%)$ are favored clearly. But these conventional technologies would lose their leading position immediately the ecological attitude turns. In scenario 6c hybrids (17.8\%) are the most probable choice. The choice probabilities of hydrogen, LPG/CNG, biofuels and electric power trains would increase likewise. This makes clear that the attitudes of individuals influence the choice probabilities for propulsion technologies - even if all available technologies are provided with the highest possible network density. Table 5 shows the simulation results in detail.

With the above discussion we provide empirical evidence regarding one aspect 
of the chicken-egg problem. The choice probabilities - and ultimately the demand - for passenger cars with alternative fuel-types strongly depend on the provided infrastructure. That is, conventional technologies will still dominate the individual road transport in future, without an expansion of fueling networks of alternatives. Such an expansion would require high investments. It is difficult to imagine that car users would not have to partly pay for it, in one way or another.

\subsection{Willingness to Pay}

On the basis of our model we are able to identify the WTP for an increasing service station network. That is, the amount $\varphi$ that a person is willing to pay in addition to the baseline price $p$ for an increase $\eta$ of the baseline network density $d$, without a change in utility. Since we let squared terms (of the purchase price as well as of the network density) enter our model the WTP do not fit in with the ratio of the corresponding coefficients of the linear terms. Due to the fixed utility level equation (3) has to hold:

$$
\begin{aligned}
V & =\beta_{p} p+\beta_{p^{2}} p^{2}+\beta_{d} d+\beta_{d^{2}} d^{2}+c \\
& \stackrel{!}{=} \beta_{p}(p+\varphi)+\beta_{p^{2}}(p+\varphi)^{2}+\beta_{d}(d+\eta)+\beta_{d^{2}}(d+\eta)^{2}+c
\end{aligned}
$$

where $\beta_{p}, \beta_{p^{2}}$ and $\beta_{d}, \beta_{d^{2}}$ denote the estimated cofficients of the price and the network density variables, respectively. $c$ is the value that the remaining independent variables of the model yield to the deterministic component of utility $V$. Simple algebraic transformations of equation (3) result in a quadratic equation in the variable $\varphi$, its meaningful solution is given by

$$
\varphi=-\frac{\beta_{p} / \beta_{p^{2}}+2 p}{2}-\sqrt{\left(\frac{\beta_{p} / \beta_{p^{2}}+2 p}{2}\right)^{2}-\frac{\left(\beta_{d}+\beta_{d^{2}} 2 d\right) \eta+\beta_{d^{2}} \eta^{2}}{\beta_{p^{2}}}} .
$$

For given purchase price $p$, network density $d$ and its increase $\eta$, this formula provides the WTP $\varphi .^{13}$

\footnotetext{
${ }^{13}$ Actually, it is the WTP for an increased service station network for diesel-fueled cars of individuals with an household income above 2000 Euro, who are living in urban areas and are average car users (with respect to preferred range and annual mileage). Since all network-
} 


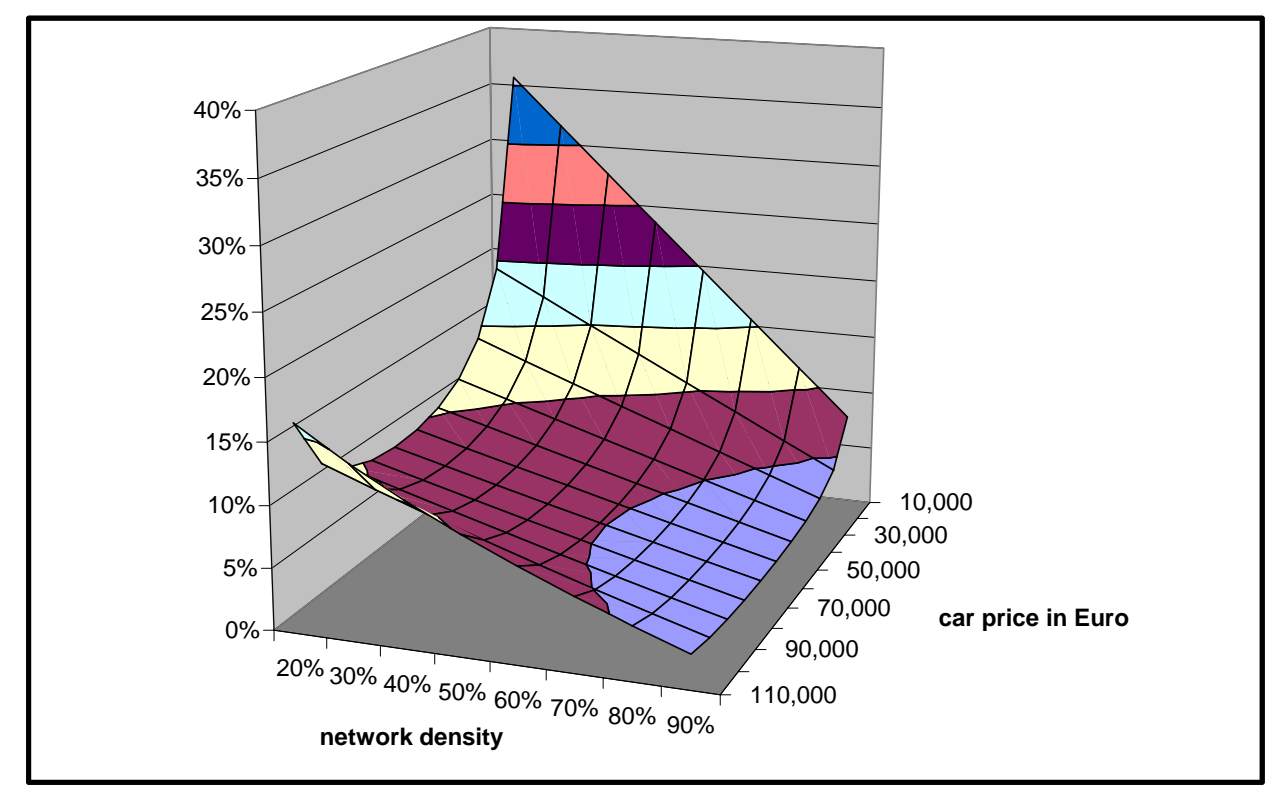

Figure 2: Relative WTP for an increase of network density (household income $>2000 €)$.

We computed the absolute WTP for $\eta=10$ (i.e. a raise of the service station network by 10 percentage points) for different baseline scenarios. Concretely, we let $p$ vary from 10000 Euro to 110000 Euro (at intervals of 10000 ), and $d$ from $20 \%$ to $90 \%$ (at intervals of 10). Table 6 shows the results in detail. By dividing these absolute terms by the corresponding baseline purchase price, we derived the relative WTP. Figure 2 illustrates their behavior. In this figure the horizontal plane, formed by the network-density-axis (which range from $20 \%$ to 90\%) and the car-price-axis (which range from 10000 Euro to 110000 Euro), defines all regarded baseline scenarios, whereas the vertical axis defines the WTP's.

The first finding is that with an increasing fueling infrastructure the WTP for further raising network density decreases. This holds for every baseline purchase price. First improvements regarding a rather underdeveloped network are valued highest by potential car buyers. For example the relative WTP on a baseline price of 10000 Euro varies extremely from about 35\% (on a baseline network of 20\%) to

interaction terms do not differ significantly from zero we interpret $\varphi$ as (an approximation of) the WTP of individuals with an household income above 2000 Euro for any enlarged service station network. 


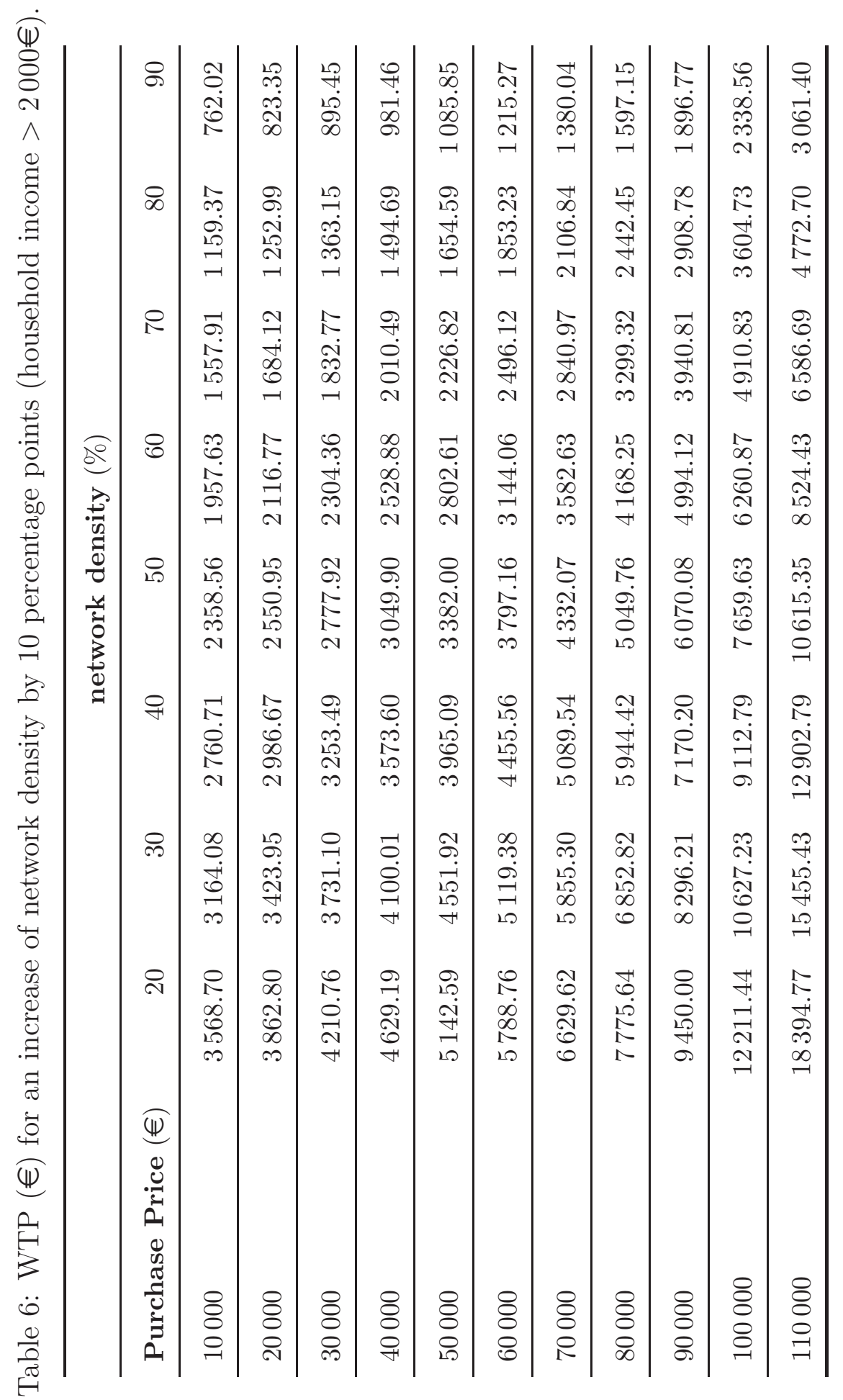




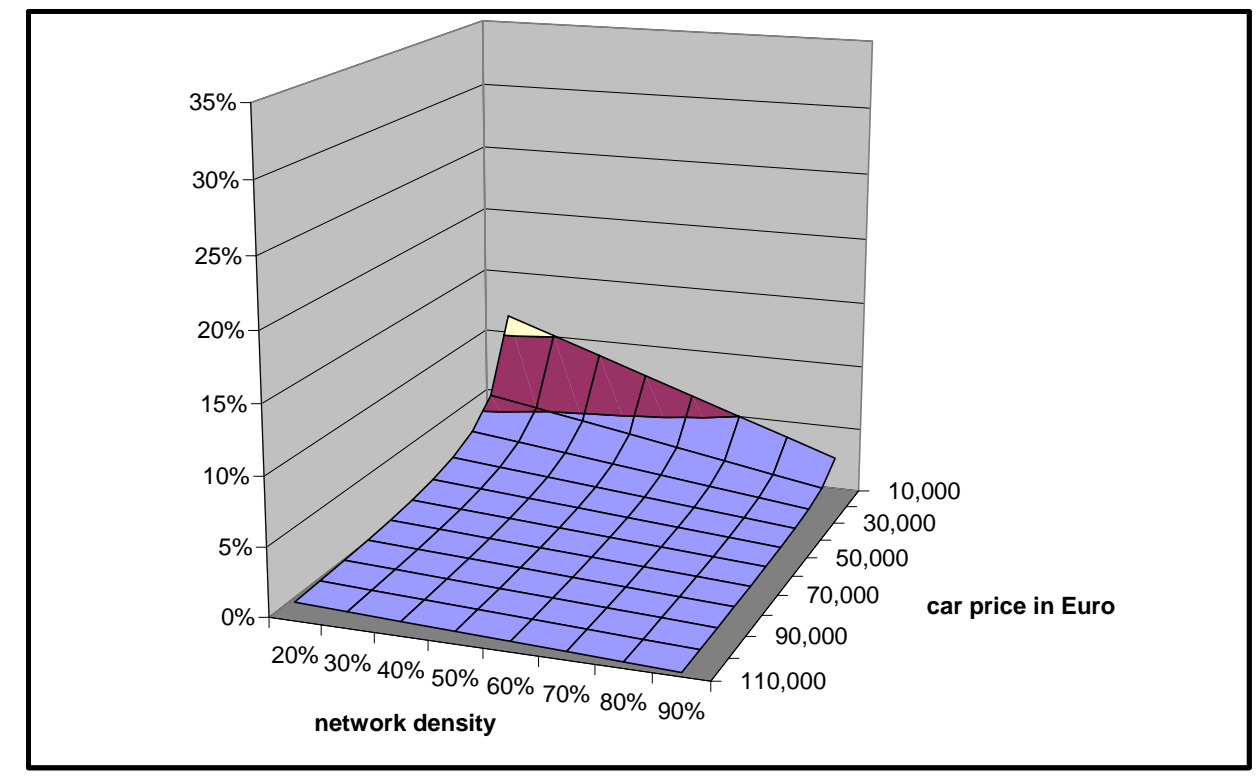

Figure 3: Relative WTP for an increase of network density (household income $<1000 €)$.

less than $8 \%$ (on a baseline network of $90 \%$ ). This result suggests that people want to be provided with an infrastructure as comfortable as possible for the respective propulsion technology - but not at any price. This is in line with the diminishing marginal utility of network density we identified above.

Secondly, we find that the relative WTP decreases with increasing purchase prices. For example the relative WTP for an enlargement of network density from $20 \%$ to $30 \%$ is falling from about $35 \%$ (on a baseline price of 10000 Euro) down to about $9,5 \%$ (on a baseline price of 70000 Euro). The negative effect of a higher purchase price is dominating the positive impact of the squared price term. But this development stops at about a baseline price of 70000 Euro. For more expensive cars the relative WTP is increasing again. This suggests that in this price category, money does not any more play that big role for purchase decisions. Here, the positive impact of the squared price term is dominating.

Note that this discussion refers to potential car buyers with a household income above 2000 Euro. For comparison table 7 and figure 3 show the absolute and the relative WTP's, respectively, for individuals of the lowest income group. ${ }^{14}$ Basi-

\footnotetext{
${ }^{14}$ To compute the WTP's in this case, we have to substitute $\beta_{p}$ in equation (4) by the sum of
} 


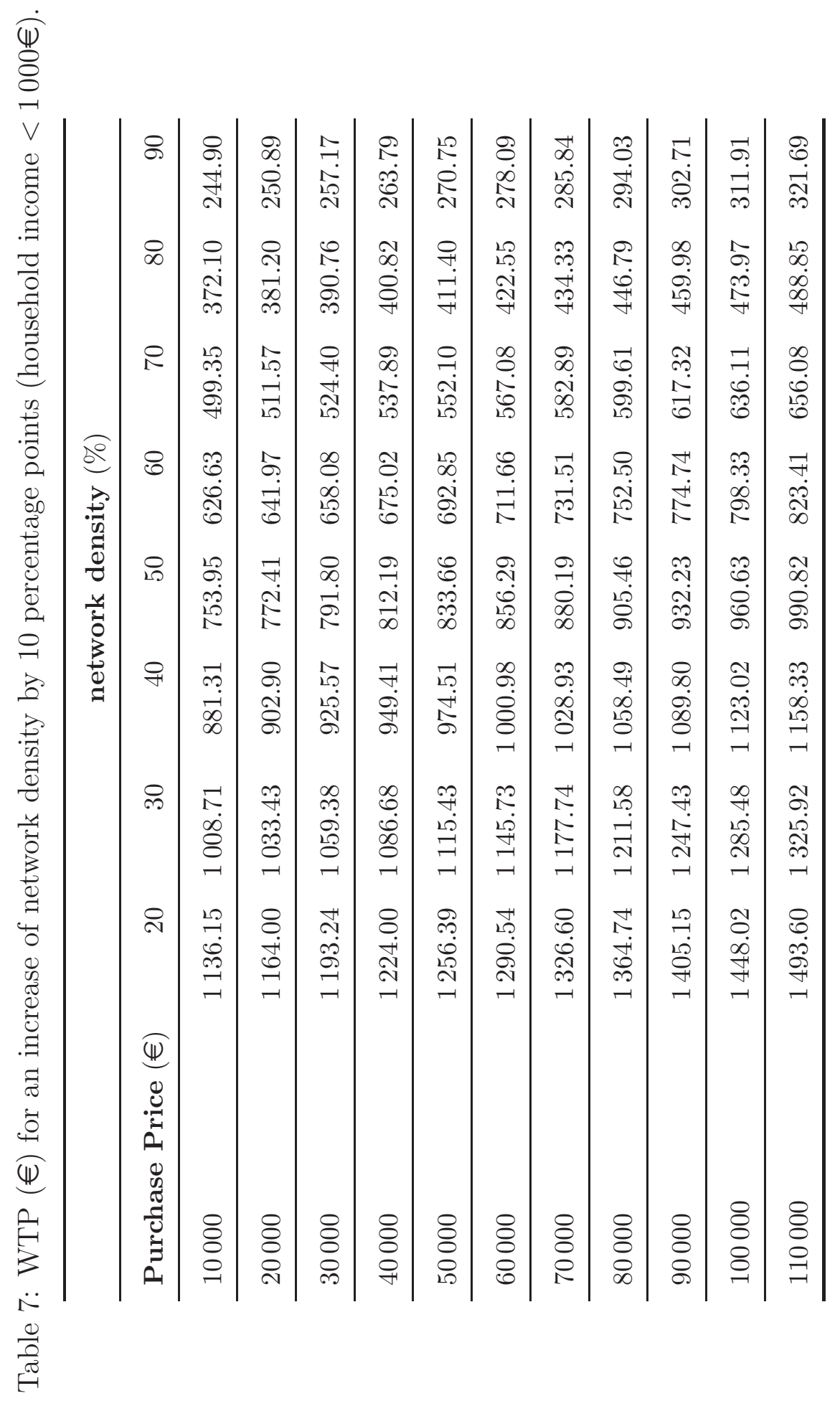


Table 8: WTP per $100 \mathrm{~km}$ car driving for an increase of network density.

\begin{tabular}{lcccccccc}
\hline network density $(\%)$ & 20 & 30 & 40 & 50 & 60 & 70 & 80 & 90 \\
WTP $(€ / 100 \mathrm{~km})$ & 2.07 & 1.84 & 1.61 & 1.37 & 1.14 & 0.91 & 0.68 & 0.45 \\
\hline
\end{tabular}

cally there are two differences. First, the discussion takes place on a different level. The WTP's are significantly lower. And second, within the observed range, the relative WTP decreases continuously with increasing baseline car prices. Despite one can assume that upper price categories are not relevant for these individuals, it illustrates how strong the negative impact of the linear price term is.

Alternatively, it is imaginable that car drivers would be participated in costs for an expansion of infrastructure by an increase in variable costs of driving. We analyze what increase in variable costs people are willing to accept for a simultaneous increase of the network density. Therefore, we proceed analogously as above. We quantify the additional variable costs $\vartheta$ that do not change the utility - given an increase $\eta$ of the baseline network density d. That $\vartheta$ is given by ${ }^{15}$

$$
\vartheta=-\frac{\left(\beta_{d}+\beta_{d^{2}} 2 d\right) \eta+\beta_{d^{2}} \eta^{2}}{\beta_{v}},
$$

where $\beta_{d}, \beta_{d^{2}}$ and $\beta_{v}$ denotes the estimated coefficients of the network density variables and the variable costs, respectively. As the baseline variable costs $v$ do not enter equation (5), the willingness to accept additional variable costs is independent from their original level. ${ }^{16}$ Table 8 shows our results.

Again, we find that with an increasing baseline network density the amount of additional variable costs that people are willing to accept for an even denser network is decreasing. Based on a network density of $20 \%$ people would be willing to pay over 2 Euro more per $100 \mathrm{~km}$ car driving. As long as the network would be upgraded to $30 \%$ their utility would not change. In comparison, people would pay less than 0.50 Euro to guarantee that they can refuel their car on all service

the coefficients of the independent variables Purchase Price and PriceXIncomeBelow1000.

${ }^{15}$ Note: Since only the linear term of variable costs differs significantly from zero, we do not consider the quadratic term for this purpose.

${ }^{16}$ Remind that variable costs take on the values 5,10 and $20 € / 100 \mathrm{~km}$ in our experimental design. 
stations - instead on nine out of ten anyway.

\section{Conclusion}

In our paper we have shown that the demand for passenger cars with alternative fuel-types strongly depends on the provided infrastructure. Without further expansions of the service station network for alternative fuels, conventional technologies will still dominate the individual road transport in the next decades. But the consumers are willing to pay for the development and many of them would switch to new technologies if the infrastructure improves.

In our simulations we have demonstrated that the consumers distinguish between different non-fossil fuel alternatives and that not all of them are equally favored. Even though the respondents of our survey were asked to imagine that the described cars in the SP-experiment were identical except for the given attributes, some technologies were more often rejected. Biofuels and electric power train were not very popular even in a situation where their infrastructure is equally developed. On the other hand, hybrids, LPG/CNG and hydrogen have the potential to be alternatives to conventional technologies.

In this regard, the question arises whether the preferences of the consumer will change over time and to what extend their attitudes towards different technologies are influenced by public opinion, political discussions and events. The unpopularity of biofuels in our data set, for instance, could be biased by the actual discussion about the rivalry between biofuel and food production. Therefore, an interesting experiment would be to repeat the survey and to compare the results.

It is also important to emphasize, that the estimations and results in our paper base upon our survey data. They are not representative for the German population even though we tried to choose the group of respondent as representative as possible. An extension of our analysis could be to weight the different consumer types in our survey with the corresponding raising factors to reproduce the composition of the German population in terms such as sex, age, income, family structure and ecological attitude. 


\section{References}

[1] Ben-Akiva, M. and S. Lerman (1985), Discrete Choice Analysis - Theory and Application to Trael Demand, Cambridge.

[2] Brownstone, D., D.S. Bunch and K. Train (2000), Joint Mixed Logit Models of Stated and Revealed Preferences for Alternative-Fuel Vehicles, Transportational Research 34B, 315-338.

[3] Brownstone, D. and K. Train (1999), Forecasting New Product Penetration with Flexible Substitution Patterns, Journal of Econometrics 89, 109-129.

[4] Bunch, D., M. Bradley, T. Golob and K. Kitamura (1993), Demand for Clean-Fuel Vehicles in California: A Discrete-Choice Stated Preferences Pilot Study, Transportation Research 27A, 237-253.

[5] Carlsson-Kanyama, A., A.-L. Linden and B. Ericsson (2005), Residential energy behaviour: does generation matter? International Journal of Consumer Studies 29, 239-252.

[6] Dragay, J.M. (2001), The effect of income on car ownership: evidence of asymmetry, Transportation Research 35A, 807-821.

[7] Erwing, G. and E. Sarigollu (2000), Assessing consumer preferences for clean-fuel vehicels: a discrete-choice experiment, J. Public Policy Mark 19, 106-118.

[8] EU (European Commission) (2000), Green Paper - Towards a European Strategy for the Security of Energy Supply.

[9] EU (European Commission) (2006), Green Paper - A European Strategy for Sustainable,Competitive and Secure Energy.

[10] Farrel, J. and G. Saloner (1986), Installed Base and Compatibility: Innovation, Product Preannouncements, and Predation, American Economic Review 76(5), 940-955. 
[11] Fowkes T. and M. Wardman (1988)The Design of Stated Preference Travel Choice Experiments, Journal of Transport Economics and Policy 22(1), 161-172.

[12] Heiss, F., (2002), Structural Choice Analysis with Nested Logit Models, Stata Journal 2(3), 227-252.

[13] Herriges, J.A. and C.L. Kling (1996), Testing the Consistency of Nested Logit Models with Utility Maximization, Economic Letters 50, 33-39.

[14] Horne,M., M. Jaccard and K. Tiedemann (2005), Improving Behavioral Realism in Hybrid Energy-Economy Models Using Discrete Choice Studies of Personal Transportation Decisions, Energy Economics 27, 59-77.

[15] Louviere, J.J., D.A. Hensher and J.D. Swait (2006), Stated Choice Methods - Analysis and Applications, fourth printing, Cambridge.

[16] Manski C. and L. Sherman (1980), An empirical analysis of household choice among motor vehicles, Transportation Research 14A, 349-366.

[17] McCarthy, P. and R. Tay (1998), New vehicle consumption and fuel efficiency: a nested logit approach, Transportation Research 34E, 39-51.

[18] McCarthy, P. (1996), Market Proce and Income Elasticities of New Vehicle Demands, The Review of Economics and Statistics, 78(3), 543-547.

[19] McFadden, D. (1974), Conditional Logit Analysis of Qualitative Choice Behavior, Frontiers in Econometrics, Academic Press, New York, 105-142.

[20] McFadden, D. (1978), Modelling the Choice of Residential Location, Spatial Interaction Theory and Planning Models, North-Holland, Amsterdam, 75-96.

[21] Train, K.E. (2003), Discrete Choice Methods with Simulation, Cambridge. 